\title{
Max Weber e a história cultural da modernidade
}

\author{
Gangolf Hübinger \\ Tradução de Paulo Astor Soethe
}

Às portas do século XX, as nações ocidentais definitivamente se transformaram em sociedades industriais. Isso, por sua vez, conduziu em toda parte a um aumento da auto-observação científica. Não foi diferente o que se deu na Inglaterra, nos Estados Unidos ou na França. No Império alemão, Max Weber foi um ator proeminente em meio a esse processo ${ }^{1}$. Como um contemporâneo politicamente engajado, experienciou a grande transformação da sociedade burguesa de elites em uma cultura democrática de massas, o que ele mesmo denomina, em determinado momento, a "democratização ativa de massas" (MWG I/15, p. 538). Weber esteve entre os observadores mais sensíveis

1. A base deste artigo é a conferência que proferi na Academia Bávara de Ciências, durante meu estágio de pesquisa no Historisches Kolleg de Munique, no ano acadêmico de 2010-2011. desse processo. Percebeu neste novas perspectivas históricas e definiu-o com métodos inovadores para as ciências sociais.

Quando o Império alemão surgiu, em 1871, e buscou ocupar seu lugar entre as potências mundiais europeias, Weber estava para completar a idade de 7 anos. Sua formação na capital Berlim foi marcada pelo ambiente político do pai, como deputado nacional-liberal na Câmara de Deputados prussiana e no Parlamento do Império, o Reichstag. Não foi menor a influência que exerceu sobre ele, no entanto, o engajamento da mãe em favor de reformas sociais. Também os parentes do lado materno contribuíram para sua formação, segundo o mundo de valores do liberalismo e protestantismo característicos do Sudoeste alemão.

Weber obteve formação acadêmica como jurista, o que fez dele, para o resto da vida, alguém conceitualmente muito rigoroso. Como docente uni- 
2. Sobre a teoria histórica da modernidade, ver Dipper (2010) e Schneider e Lutz (2008). versitário, ele migrou para a economia política [Nationalökonomie] e sempre valorizou um primado da economia. Sua paixão intelectual, no entanto, sempre se voltou mais e mais "ao fato de a cultura moderna ter se tornado assim e não de outro modo". Isso o compeliu ao campo da "história”, e é isso que pretendo assinalar com o título deste texto.

Por isso cabe agora precisar brevemente o que entendo por "modernidade" [Moderne]. A pesquisa mais recente emprega o termo "modernidade" como categoria da história vivida enquanto conceito temporal; com isso, distingue-o do conceito puramente estrutural-analítico de modernização, embora haja certa labilidade no limite entre um e outro. $\mathrm{O}$ que significa que sociedades se descrevam e se experienciem forçosamente como "modernas", tal como ocorreu por volta de 1900? Para uma teoria histórica da modernidade ${ }^{2}$, isso implica investigar quais são os domínios da vida social em que os contemporâneos identificam rupturas entre formas de vida tradicionais e modernas e qual a maneira como eles reajustam a relação entre presente e passado. Ao mesmo tempo, cabe perguntar quais são as linhas de desenvolvimento supostas por esses contemporâneos, nas quais a "modernidade" se move de maneira dinâmica. (Entre as expressões preferidas de Max Weber, está notadamente o conceito de "tendências de desenvolvimento".) Decisivo é saber quais são as batalhas culturais travadas por uma época em torno da primazia interpretativa sobre o que se contempla como conduta e ordenação "modernas" da vida e sobre o que se desqualifica como antimoderno. A experiência fundamental da modernidade não é somente a da "aceleração". Não menos característica é a experiência da tensão permanente entre imagens de mundo concorrentes entre si - religiosas e seculares, por exemplo -, que não se deixam mais hierarquizar. "Segundo as posiçôes últimas de cada singular, um é o demônio e o outro é o deus; e cada um precisa decidir qual é o seu demônio e qual é o seu deus" (MWG I/17, p. 101) - eis a maneira drástica como Weber explicará, mais tarde, esse traço fundamental da modernidade a seus estudantes de Munique, em "A ciência como profissão".

Segundo destaca Max Weber, a época em torno de 1900 - com seus partidos de massa, ideologias, vanguardas artísticas, ondas fundadoras de institutos sociológicos e explosão de revistas científicas - oferece muitos exemplos dessa coação moderna à decisão entre bom e mau, verdadeiro e falso. Weber evita a forma do coletivo singular "a modernidade", ainda pouco usual. Ele prioriza o adjetivo, que emprega muitas vezes, no entanto: “o homem moderno", "a vida moderna”, “a cultura moderna”. 
Surpreende como, em trechos decisivos, Weber gosta de se referir a "problemas histórico-culturais" ou "fenômenos histórico-culturais". É minha intenção lançar novo olhar sobre Weber como pensador da história, em sua análise da modernidade, pois causa estranhamento que o debate sobre "Weber, o historiador" tenha alcançado seu ponto alto em meados dos anos de 1980 (como em 1985, na Jornada Internacional de Historiadores de Stuttgart $)^{3}$ para depois - justamente em meio ao ímpeto do cultural turn - sofrer uma interrupção abrupta. Nessa mesma época, vieram a público os primeiros volumes da edição histórico-crítica da Obra completa de Max Weber (MWG). E minha tese volta-se a um dado dessa edição. À medida que documenta os escritos de Weber em seu desenvolvimento e a maneira como eles se situam nos contextos culturais e da história da ciência, ela deixa uma coisa clara: todos os temas com os quais Weber trabalha (a economia de mercado capitalista, as religiōes mundiais, o Estado moderno etc.) são vistos por ele sob uma perspectiva histórica. Isso se aplica desde sua tese de doutorado Sobre a história das sociedades comerciais na Idade Média, de 1889 (cf. MWG I/1), até o curso inacabado sobre a gênese e estrutura do Estado moderno, do semestre de verão de 1920, em Munique $e^{4}$ Weber e as ciências sociais de seu tempo propuseram-se a enfrentar a mesma questão que historiadores de hoje também enfrentam. Assumiram para si "problemas da história universal" e pretenderam encontrar uma nova via de acesso à história mundial.

Em favor de minha tese, recorro à visão de Reinhart Koselleck sobre por que não se pode, em especial na Época Moderna, simplesmente escrever a história de maneira contínua, sendo preciso reescrevê-la muitas e muitas vezes. Koselleck supóe haver um nexo de efeito entre uma transformação social da experiência e uma mudança de métodos e perspectivas científicas. Ele considera uma premissa antropológica que a experiência da realidade e a "elaboração" científica consciente da realidade "sempre remetam uma à outra, fundamentem-se reciprocamente, sem que, no entanto, se possa derivar plenamente uma da outra" (Koselleck, [1988]* 2000, p. 33).

Max Weber e sua época oferecem objeto especialmente propício a testar essa interação. Na pesquisa especializada, costuma-se destacar o limiar cultural por volta de 1900 como uma "época axial" para a cientificização da autoobservação social. O impulso, talvez pela última vez, ainda vem da Europa e, segundo demonstrou Jürgen Osterhammel em um capítulo contundente de sua história universal; disso as ciências dedicadas ao diagnóstico de época teriam tomado o conceito de "auto-observação", assumido pelas ciências dedicadas ao diagnóstico de época ${ }^{5}$. Esse limiar cultural, eis meu ponto de
3. Cf. Kocka (1986) e, nesse volume, sobretudo Mommsen (1986). Dessa mesma época, sobre a ligação profícua entre história e sociologia, ver Roth (1987, pp. 283-302). Mais tarde, foi mais frequente discutir aspectos de teoria da história: ver Jaeger (1994), Barrelmeyer (1997) e Hidas (2001). Como resultado de trabalhos editoriais relacionados com a Ética protestante e mais amplamente direcionados ao pensamento histórico de Weber, ver Gosh (2008).

4. Trata-se de "Allgemeine Staatslehre und Politik (Staatssoziologie): Unvollendet. Mitund Nachschriften 1920" (cf. MWG III/7).

* A data entre colchetes refere-se à edição original da obra. Ela é indicada na primeira vez que a obra é citada. Nas demais, indica-se somente a edição utilizada pelo autor. [N. E.]

5. "Só a partir dos anos de 1890 foi que a sociologia acadêmica passou a contribuir com maior amplitude para a investigação empírica de sociedades contemporâneas. Só então se iniciava - cada vez mais institucionalizada, até os dias de hoje - a auto-observação metódica de sociedades em grau avançado de modernização" (Osterhammel, 2009, p. 56). 
partida, revela-se aos contemporâneos intelectualmente "musicais" - Max Weber entre eles - como uma transformação de experiências em quatro domínios centrais:

1. A experiência do capitalismo como a "potência mais prenhe do destino de nossa vida moderna”.

2. A crise do historismo como crise da compreensão científica da "realidade que nos cerca".

3. A experiência da cultura de massa pluralizada, com suas lutas de interesses e ideias reforçadas pela mídia.

4. A experiência do mercado político de massas como processo de "democratização ativa das massas”.

Max Weber reagiu a essa transformação da experiência e às grandes tensões do desenvolvimento cultural moderno como um "observador engajado" (Raymond Aron) avant la lettre. Com o intento de trabalhar a especificidade de seu pensamento sócio-histórico e histórico-cultural, descreverei a seguir de que maneira isso ocorreu, em quatro itens que, grosso modo, correspondem a quatro fases de sua obra:

1. A história econômica - a história do capitalismo - oferece-nos um fio condutor que perpassa toda a obra de Weber.

2. Exigem-se novas formas de conhecimento: o primado dos problemas e a escolha da perspectiva tornam-se para ele o pressuposto do conhecimento histórico.

3. Weber propõe uma questão central para a história cultural: como é que ideias se tornam efetivas na história? Qual a peculiaridade do desenvolvimento cultural europeu?

4. Aqui é a Primeira Guerra Mundial que dita os problemas e as perspectivas: a concentração sobre o poder e a dominação, em especial sobre a gênese e a estrutura do Estado e da democracia modernos.

Em Obra completa de Max Weber, dedica-se muito esforço para situar os escritos, os cursos e as cartas do autor na cultura científica alemã e europeia por volta de 1900. E uma imagem delineia-se aqui de forma cada vez mais nítida: a de Weber como historiador da economia. Em Berlim, estavam à 
disposição do jovem doutorando as bibliotecas de alguns eruditos importantes. Recentemente se descobriu a biblioteca particular de Levin Goldschmidt (1829-1897), orientador de doutorado de Max Weber e primeiro titular da cátedra de direito comercial da universidade de Berlim. Weber utilizou essa biblioteca durante a redação de sua tese (mencionada há pouco) sobre sociedades comerciais na Idade Média: era uma tese de direito em campo econômico ${ }^{6}$. Weber irá ampliar o alcance universal de seus estudos no percurso que se estende de sua tese de livre-docência sobre $A$ história agrária romana em sua importância para o direito público e privado (cf. MWG I/2), passa pelas relações agrárias na Prússia moderna e, por fim, alcança os escritos sobre a bolsa de valores, que o levam até o núcleo das transações modernas de mercadorias e títulos de valores (cf. MWG I/5). Weber aprecia esse arco que vai da Antiguidade ao presente, ou, dito de maneira mais correta, do presente até a Antiguidade; e maior ainda é seu empenho quando estão em questão a gênese e a força modeladora do capitalismo moderno.

Em 1904, depois de superar uma grave doença psicossomática, Weber aproveitou a chance de investigar a modernidade justamente onde o capitalismo florescia com mais robustez: nos Estados Unidos da América. Ele aceitou o convite para participar de um congresso de eruditos no âmbito da Exposição Mundial de St. Louis, naquele ano. Antes da Primeira Grande Guerra, as exposições mundiais eram as grandes arenas da rivalidade global entre as nações industriais. Como já havia sido o caso em Paris no ano de 1900, também agora em St. Louis, quatro anos depois, os congressos de eruditos, espetaculares em si mesmos, eram - como os jogos olímpicos, a propósito parte dessa mostra dos grandes feitos mundiais. A delegação alemã de notáveis foi composta, além de Weber, por Ernst Troeltsch, Adolf von Harnack e Karl Lamprecht. Cada um deles procurou converter suas experiências em interpretaçôes histórico-culturais, e nisso Lamprecht (2006) foi decerto o mais artificioso ${ }^{7}$. As cartas de viagem de Max Weber, escritas à maneira de um diário, dão testemunho da peculiar intensidade com que ele viveu a experiência do novo mundo capitalista. Quando se diz "experiência” temse em mente o sentido literal do termo, como exploração e descoberta do espaço, e também como investigação crítica empreendida com o aparato de um economista escolado, que interpreta os sinais da transformação de uma sociedade agrária em uma sociedade do alto capitalismo.

Ao chegarem à Nova York no dia 30 de agosto, Max e Marianne Weber, do quarto de seu hotel na Broadway, tiveram vista direta para a primeira geração de arranha-céus da cidade; eles os perceberam como as novas for-
6. Em detalhe na nota editorial ao volume MWG I/ 1 , em especial nas pp. 112-136.

7. Sobre isso, ver Chickering (1993, pp. 345-350). 
8. A viagem de Max e Marianne Weber está agora excelentemente pesquisada e exposta em Scaff (2011).

9. Esse texto, ainda não publicado, fará parte da seção II do volume 4 da edição alemã de Obras completas de Max Weber, organizado por Gangolf Hübinger, M. Rainer Lepsius em colaboração com Thomas Gerhards e Sybille Osswald Bargende, cujo lançamento está previsto para 2014. talezas do capitalismo. Mais duras ainda foram as impressões em Chicago, a city of the big shoulders, ainda mais norte-americana. Weber visitou matadouros gigantescos, que com seus novos métodos de produção deviam suprir o consumo maciço de carne barata. De quebra, presenciou lá uma greve, debelada com violência ${ }^{8}$.

A própria St. Louis, com a reunião dos colegas, acabou com seu bom humor. Originalmente, sua intenção era esclarecer o público internacional acerca do debate alemão sobre a constituição social germânica antiga. Os organizadores do evento dissuadiram-no, porém, de falar sobre esse tema tão específico, e Weber discursou, de modo mais abrangente, sobre os processos de transformação de sociedades agrárias ocasionados pelo capitalismo. $\mathrm{O}$ assunto era atual e bem se aplicava à Prússia, assim como à frente de expansão no Oeste norte-americano. E ele foi exatamente para lá. Enquanto a delegação alemã seguiu para Washington, para participar da recepção oferecida pelo presidente norte-americano, Weber viajou por conta própria na direção contrária, até o Oeste - ao território indígena em Oklahoma.

No dia 30 de setembro, ele se encontra no vilarejo de Muskogee em uma praça de leilóes e observa como os índios creek e os cherokee vendem aos fazendeiros e especuladores brancos as terras que lhes haviam sido destinadas: "Amanhã ocorrerá um leilão de terras de Creekland, que presenciarei; virão 5 mil creeks, ficarão todos acampados em suas tendas, e receberão o pagamento, que dividirão entre si”, anota ele 9 . A cidade da frente de expansão ainda é território indígena; três anos mais tarde, tornar-se-á o novo estado federado de Oklahoma. Como economista, Weber percebe rapidamente os enormes conflitos de interesses entre as tribos indígenas, fazendeiros, construtores de ferrovias e administração estatal, que colidem de forma evidente em um lugar como aquele. Weber toma gosto pela atmosfera de aventura:

A movimentação aqui é fabulosa, e para mim não há saída: isso tudo exerce sobre mim um encanto poderoso, apesar do fedor e bafio de petróleo, dos yankees cuspindo e do barulho abjeto dos muitos trens de sineta [...]. Os "advogados" dão a impressão de valentōes irresponsáveis - mas predomina uma espontaneidade fabulosa e travessa, mantida pelo respeito mútuo que sempre se trata de manter em vista [...]. Há mais civilização aqui que em Chicago.

Eis a impressão de Weber, que escreve logo a seguir, no entanto: "Pena em questão de um ano tudo aqui vai estar como em Oklahoma[-City], ou 
seja, como em qualquer outra cidade da América. Com um ímpeto irrefreável, tudo que se põe no caminho da cultura capitalista” será aniquilado.

Da frente de expansão no Oeste, sua viagem exploratória levou-o até a color line, no Sul. O casal Weber visitou o Booker T. Washington's Tuskee Institute, em Alabama, a primeira universidade para negros. A impressão mais forte causou-lhe, porém, o líder negro e professor de história William E. B. Du Bois, em Atlanta. Weber conseguiu de Du Bois, para publicação em sua revista Archiv für Sozialwissenschaft und Sozialpolitik [Arquivo para a Ciência social e Política social], o artigo "A questão dos negros nos Estados Unidos"10.

Durante a viagem, sempre que possível Weber foi um observador participativo de cultos das mais diversas comunidades religiosas, a começar com os imigrantes alemães no Norte até os southern baptists na Carolina. Weber já trouxera consigo a temática histórico-cultural da ética das denominações protestantes e da mentalidade econômica do capitalismo, pois a primeira parte de $A$ ética protestante já estava escrita. Contudo, o politólogo norte-americano Lawrence Scaff (2011, p. 3) tem razão ao ver na viagem de Weber à América um turning point em sua obra. A representação da comunidade religiosa torna-se mais vivaz e duradoura. Disso também tiram proveito os historiadores. Weber, com A ética protestante, quer demonstrar a estes últimos como “as 'ideias' em geral se tornam efetivas na história” (Weber, 1920b, p. 83). As ideias ganham sua força social configuradora em uma estrutura de efeitos disposta em diversas camadas (cf. Lepsius, 2003, pp. 35 ss.): profetas, teólogos e "intelectuais" formulam conjuntos articulados em si mesmos de ideias religiosas sobre deus e o mundo. Pastores, professores e publicistas as traduzem em máximas para a conduta de vida cotidiana e para as éticas profissionais. Comunidades religiosas, "seitas", delimitam-se por meio de um cânone de valores e criam regras de inclusão e exclusão. Se uma tal ordenação da vida revela-se adequada - por incrementar os rendimentos do trabalho, por exemplo -, ela causa efeitos sobre o comportamento das pessoas no entorno. Originam-se padróes comportamentais economicamente relevantes que, na Europa moderna, se desprendem de seus nexos de fundamentação religiosa. Nos Estados Unidos, ao contrário, o vínculo religioso ainda se mantém muito mais forte. Mesmo que nesse ínterim a pesquisa especializada tenha superado em muitos aspectos os conhecimentos empíricos de Weber, sua concepção metodológica continua inspirando, como antes, a história cultural e a história econômica.

Com sua concepção, Weber visa a um "conhecimento cultural histórico pleno", segundo o denomina diversas vezes. O que se tem em mente com
10. O nome saiu equivocadamente na revista como "Burghart" du Bois (cf. Du Bois, 1906). Há ali uma nota da redação inusual, provavelmente escrita por Max Weber: "A publicação a seguir, assim como uma série de outras novas publicações de negros e sobre negros nos Estados Unidos serão comentadas criticamente nos próximos números por um dos editores; assim por certo haverá ocasiāo de se analisar com maior profundidade alguns aspectos objetivos do problema. Por ora alegramo-nos em poder dar ensejo à manifestação de um dos mais proeminentes representantes científicos dos negros americanos". Um fórum de discussão como se tinha em vista naquele momento, no entanto, não se concretizou na Archiv für Sozialwissenschaft und Sozialpolitik. 
isso? Para Weber, todos os fenômenos culturais, sejam as religiōes, o gosto artístico de uma época ou o "Estado" como formação normativa, devem ser submetidos em primeiro lugar ao seguinte questionamento: de que maneira estão economicamente condicionados? Nisso ele segue Karl Marx, que tanto preza. Mas a seguir também é preciso propor a questão em via inversa: em quais efeitos os fenômenos culturais se tornam economicamente relevantes? (cf. Weber, 1973c, pp. 162-164). Somente esse procedimento metodológico duplo possibilitaria o almejado "conhecimento cultural histórico pleno". Em face da cisão do pensamento histórico contemporâneo em turns cada vez mais atomizados, que se substituem uns aos outros cada vez mais rapidamente, vale trazer de novo à lembrança esse postulado de uma formação histórica do método.

A "crise do historismo" era parte desse limiar cultural europeu por volta de 1900, no qual - segundo as palavras de Ernst Troeltsch, amigo de Weber - "tudo estremece". Mais que os historiadores especializados, Max Weber sentiu-se desafiado por essa crise a ancorar metodicamente de modo novo o "conhecimento cultural histórico".

"Conhecimento histórico-cultural pleno" - esse desiderato não conduz às trilhas de um positivismo europeu álacre, como o que propagavam Henri Berr e a Revue de Synthèse Historique no Congresso Internacional de Historiadores de 1900, em Paris (cf. Hübinger et al., 2010). Quando em 1904, antes de sua viagem à América, Weber assumiu o já mencionado Archiv für Sozialwissenschaft und Sozialpolitik, ele escreveu para a revista uma diretriz de crítica do conhecimento que até hoje constitui um desafio às ciências históricas da cultura: o famoso artigo "A 'objetividade' do conhecimento na ciência social e na política social". Esse texto pode ser lido sem dificuldade também como uma doutrina histórica [Historik], bem no sentido de Johann Gustav Droysen: como o lugar em que confluem sistematicamente todas as dimensōes da pesquisa e da exposição históricas. Renuncio a caracterizar mais intensamente as linhas teórico-históricas; darei importância a apenas dois aspectos.

Weber promete às ciências históricas da cultura uma "juventude perene",

11. Ver, em geral, a crítica ao livro de Eduard Meyer datado de 1902 (cf. Weber, 1973d). desde que se despojem da crença em um naturalismo dos fatos e assumam como sua tarefa a "ordenação intelectual dos problemas" que dominam uma sociedade (Weber, 1973c, pp. 206, 166) ${ }^{11}$. Com o primado dos problemas 
sobre os fatos, Weber revolve a ferida deixada pela experiência incômoda que se faz notar pela primeira vez com a crise do historismo: que cada geração, embora não escreva sua história de maneira completamente nova, reescreve-a sempre de maneira significativa. Cientistas da cultura devem ser especialistas em

[...] conferir ordem ao caos daqueles fatos que, a cada vez, integramos ao círculo de nosso interesse. $\mathrm{O}$ aparato intelectual que o passado desenvolveu por meio da elaboração reflexiva da realidade imediatamente dada - ou melhor: por meio da reconfiguração reflexiva dessa realidade - e por meio da ordenação naqueles conceitos que correspondem àquele estágio de seu conhecimento e à direção do seu interesse confronta-se permanentemente com o que podemos e queremos obter da realidade em termos de novos conhecimentos (Idem, p. 207).

O tópico decisivo aqui é a "reconfiguração reflexiva" [denkende Umbildung]. "Nessa luta é que se realiza o progresso do trabalho na ciência cultural" (Idem, ibidem).

Weber denomina "reconfigurar", exatos oitenta anos depois, o que Reinhart Koselleck denomina "reescrever" a história. E o que Koselleck agrega a isso como "transformação da experiência e mudança metodológica" - citei acima a passagem - Weber incorpora à metáfora, mais compacta e fácil de memorizar, da mudança de ponto de vista, no final de seu artigo sobre a objetividade: "A luz dos grandes problemas culturais deslocou-se para mais além. Então a ciência prepara-se também para mudar a sua posição e o seu aparelho conceitual, e das alturas do pensamento fitar o fluxo do que ocorre" (Idem, p. 214).

Daquele primado dos problemas, Weber deriva a tese, defendida de maneira muito aguerrida, de que o conhecimento histórico só seria possível sob "pontos de vista especificamente isolados, diversos e muito heterogêneos entre si" (Idem, p. 184). "Pontos de vista", aqui, nada tem de conceito cotidiano. Weber é um perspectivista radical. No artigo sobre a objetividade, o conceito "pontos de vista" aparece nada menos que dezessete vezes, sempre sob grande concentração teórica. Pode ser que isso tenha mais a ver com o historiador da cultura Jacob Burckhardt do que sabíamos até agora. $\mathrm{Na}$ "Introdução" ao curso sobre a história cultural da Grécia ${ }^{12}$, lemos que fatos e acontecimentos se aprendem com livros; "o que nos cabe, por outro lado, é estabelecer pontos de vista para os acontecimentos" (Burckhardt apud Nippel, 1993, p. 253). Max Weber leu ativamente essa introdução, com o
12. Trata-se de "Einleitung zur Griechischen Kulturgeschichte”, cuja transcrição foi publicada em Oeri (1905). 
lápis na mão, e assumiu para si a seguinte máxima: "O único caminho para superar a falta de clareza dessa formulação é a constatação conceitual clara e acurada dos diversos pontos de vista possíveis" (Weber, 1973c, pp.184, 212). Por isso os weberianos são, com frequência, tipificadores irrefreáveis movidos por uma intenção comparativa. Na história das cidades, campo de pesquisa muito estimulado por Weber, ele investiga o significado da cidade antiga e medieval como célula-mãe da civilidade ocidental, em comparação contrastiva com as cidades asiáticas (cf. MWG I/22-5).

Foi a escritora Virginia Woolf, provavelmente, quem deu a expressão mais bela à consciência geral de que por volta de 1900 se vivia no limiar de uma época. Ela soube dizer até mesmo a data exata deste: "In or around December 1910, human character changed" (Woolf apud Blom, 2009, p. 319). As ciências sociais europeias o perceberam um pouco antes e reagiram a isso. Alteraram os instrumentos e as instituições da autoinvestigação social. Em 1895, foi fundada a London School of Economics, em concorrência com Oxford e Cambridge na ordenação do saber. Ao mesmo tempo, começou em Paris a controvérsia acerca da Nouvelle Sorbonne e da valorização da ciência social na França republicana.

$\mathrm{Na}$ Alemanha guilhermina, um marco foi a fundação da Sociedade Alemã de Sociologia, em 1909-1910, com Max Weber como força motriz intelectual. Ele sugeriu dois campos de pesquisa para lançar uma sonda até o centro da auto-observação moderna. De um lado, ele vislumbrava uma "sociologia das associações". Aqui ganha forma a experiência na América, pois Weber percebeu os Estados Unidos como "a terra par excellence das associações". Estas são os lugares decisivos para cunhar personalidades autoconscientes e orientadas por valores, mas também são, politicamente, lugares da democratização. Sua tese é a seguinte: "A democracia na América não é um monte de areia, mas um tumulto de seitas, associações e clubes exclusivos" (Weber, 1924a, p. 443). Weber quis saber como isso se deu em comparação com a Alemanha e a Europa. Como as sociedades modernas se auto-organizaram, no espaço social livre entre as ordenaçóes da família e as do Estado - no amplo espectro que vai do clube de bocha ao partido político e à seita literária de um poeta como Stefan George.

A mesma pergunta sobre a constituição individual do caráter e sobre as ordenações culturais supraindividuais na modernidade é o que motiva seu 
segundo projeto: uma enquete sobre a imprensa e o sistema de comunicação. Por volta de 1900, a imprensa de massa havia superado a marca de um milhão de exemplares diários. Ela era considerada como o fenômeno cultural da modernidade. O jornalista vienense Emil Löbl escreveu em 1903 Cultura e imprensa. Foi a primeira tentativa bem-sucedida de apresentar, em seus

[...] milhares de funções e influências, [...] [a] imprensa, essa grande ferramenta de movimentação intelectual, esse acumulador de todas as forças espirituais, esse guia e sedutor dos povos, benesse e flagelo de nossa época, um porta-estandarte da verdade e um defensor da mentira, um fator de elevação moral e um suscitador dos instintos mais baixos (Löbl, 1903, pp. 1 ss.).

Max Weber assumiu esse mote quando sugeriu à Sociedade Alemã de Sociologia que pesquisasse empiricamente a imprensa moderna. A concepção weberiana que se aplica, no início do texto, a questôes sobre a necessidade de capital, volta-se, no final, porém, à

[...] participação do jornalismo no teor material dos bens culturais modernos e a sua influência ubíqua, uniformizadora, objetivante e, mesmo assim, continuamente tingida emocionalmente, que a imprensa exerce sobre a situação sentimental e os hábitos de pensamento do ser humano moderno, sobre a atividade política, literária e artística, sobre a educação e o esgarçamento dos juízos e das crenças da massa (Weber, 1910, p. 28) $)^{13}$.

A semântica cultural acumulada demonstra, na época, um deslocamento do interesse científico. A assim chamada "questão social", a questão das condiçôes materiais de vida e a integração dos trabalhadores assalariados nas sociedades industriais altamente desenvolvidas parece ter sido resolvida em seus pontos centrais e agora recua para as coxias. Em primeiro plano, aparece a "questão cultural"; em Weber, de modo bem característico (como citado): o ser humano moderno e os bens culturais modernos.

Nesse ínterim, a pesquisa especializada em Weber passou a dar muita ênfase ao fato de ele ter realizado, em torno de 1910, uma "descoberta" de grande alcance. Com o novo livro de Dieter Henrich, Werke im Werden [Obras em devir] também se poderia dizer: um insight revelava a Weber o traço central da concepção de toda sua obra (cf. Henrich, 2011). Trata-se do insight-segundo a formulação marcante de Weber (1920b, p. 12) - de
13. Esse texto, ainda não publicado, fará parte da seção I do volume 13 da edição alemã de Obras completas de Max Weber, organizado por M. Rainer Lepsius. Ver formulação semelhante em Weber (1924a, p. 441). 
14. Sobre a gênese da obra, ver Wolfgang Schluchter (MWG I/24). que um "encadeamento de circunstâncias" específico resultaria na "peculiaridade específica do racionalismo ocidental e, no interior dele, do moderno racionalismo ocidental". Nas controvérsias mundo afora sobre a história da globalização e suas implicações eurocêntricas, essa "peculiaridade do racionalismo europeu" difundiu-se como sendo a "questão weberiana".

O cientista da religião Hans G. Kippenberg comenta, em Obra completa de Max Weber, que a impressionante intensidade de trabalho decorrida dessa "descoberta" por volta de 1910 se deveria ao fato de Weber haver vislumbrado um acesso completamente novo à "história cultural" (cf. MWG I/22-2, p.19). Isso me parece perfeitamente correto. $\mathrm{Na}$ época, Weber concebe o "Grundriss der Sozialökonomie" [Manual de economia social], em vários volumes e aproxima-se cada vez mais das "formaçôes culturais" cujo processo de racionalização moderno pretende descrever: a economia, o direito, o Estado, a religião; disso surge Economia e sociedade ${ }^{14}$. Trata-se sempre do jogo de trocas entre ordenaçóes racionais da vida e a conduta de vida metódica, pois nele reside toda a dinâmica da transformação histórica - este é o núcleo "históricocultural" weberiano. A Europa teria sido marcada, em seu cerne, pela crença cientificamente fundamentada de que se pode, pelo cálculo, dominar todas as coisas no mundo (cf. MWG I/17, p. 87). O tipo humano europeu seria o homo calculans na história e no presente. Weber evita estritamente a narrativa contemporânea do "progresso" ou da "decadência". Seu diagnóstico de época fixa-se na grande ambivalência da modernidade: por toda parte, o ser humano moderno conquista novos espaços de "liberdade" democratizados e constrói para si "capas rígidas de aço” de subserviência institucional.

\section{IV}

A experiência de 1914 não desviou Weber desse big theme, mas os acentos se deslocaram. A autodestruição da Europa durante a Primeira Guerra Mundial voltou a despertar o animal politicum que havia nele. Revigoradas pela Revolução Russa de fevereiro de 1917 e pela entrada dos Estados Unidos na guerra em abril do mesmo ano, todas as energias da auto-observação histórica dirigiram-se todas para os problemas do poder estatal e das ordenações políticas precárias. Weber, como erudito-intelectual, agia agora em três papéis. Com insistência, ele procurou ser aproveitado nas cúpulas de aconselhamento político. Ele empenhou uma pena mordaz e com os seus artigos sobre o estilo político de Guilherme II, levou o jornal Frankfurter Zeitung a ficar em situação difícil com a censura (cf. MWG I/15, p. 424 ss.). 
E o mais importante: retornou à universidade, com uma nova ênfase na teoria do Estado e na política.

Pois a situação da vida pessoal de Weber havia mudado. A fortuna familiar estava comprometida pelos empréstimos compulsórios de guerra, e depois de dezesseis anos como intelectual independente, ele precisou retornar à cátedra. A faculdade de direito de Bonn e a faculdade de economia de Munique o disputavam. A decisão deu-se em favor de Munique, em grande parte porque Else Jaffé vivia nas proximidades, no vale do Isar. Antes disso, porém, Weber já demonstrara grande simpatia pela cidade: "Munique é uma cidade muito 'mais democrática' que Heidelberg", escreveu em carta à sua irmã Lili Schäfer, em novembro de 1915 (MWG II/9, pp. 187 ss.). No início do verão de 1919 , viu-se em meio às agitações revolucionárias. $\mathrm{Na}$ época, ele já era conhecido dos cidadãos de Munique em razão de sua campanha apaixonada em favor da república democrática, nos discursos eleitorais em favor do Partido Democrata Alemão (DDP). Seus dois discursos espetaculares, "Ciência como profissão" e "Política como profissão" já tinham sido ouvidos pelos estudantes livres ${ }^{15}$ (cf. MWG I/17). Sua reação ao indulto concedido ao assassino de Kurt Eisner, governador da Baviera, por sua vez, irritou os estudantes das associações nacionalistas. Um dia depois da concessão do indulto ao conde Arco-Valley, Weber fez uma declaração pessoal no início de sua aula: "Por mais corajoso que tenha sido o comportamento do conde Arco: era preciso fuzilá-lo” (MWG I/16, p. 270).

Em Munique, seu novo local de atuação, Weber era um fenômeno intelectualmente provocador. Iniciou suas aulas em junho de 1919, imediatamente após seu retorno como membro da delegação alemã nas negociações de paz de Versalhes. Seu primeiro curso - na cátedra que fora de Lujo Brentano e que, no contexto das negociações de sua ida a Munique e segundo seu desejo, passou a ser designada como "Ciência social, história econômica e economia política” - tinha por objeto "as categorias gerais da ciência social”. Para maioria dos estudantes, esse curso era considerado muito abstrato. "Bagas selecionadas [...] sem nada dentro", reclamava o progressista Helmuth Plessner. Para o semestre de inverno, pediram-no o "Compêndio de história universal social e econômica". E, no semestre de verão de 1920, Weber esforçou-se ainda mais por associar, de modo acessível, história universal e análise contemporânea. Como tema, escolheu "Teoria geral do Estado e política (sociologia do Estado)". O anúncio da disciplina naquele semestre ficou registrado em um manuscrito de próprio punho (cf. MWG III/7, pp. 64 ss.). Antes do parêntese, uma formulação típica desde o século XVIII para os
15. Ou seja, aqueles não filiados às corporaçôes estudantis. [N. E.] 
16. Ver o artigo de Rita Aldenhoff-Hübinger neste Dossiê. [N. E.]

17. Para uma reprodução feita segundo critérios de crítica textual, ver MWG $I I / 7$, p. 66; a sequência de temas foi anotada na taquigrafia de Gabelsberg por Erwin Stölzl (1893-1947), que no fim de sua vida exerceu o cargo de diretor no Departamento Agrícola de Munique. cursos de história e teoria do Estado; entre parênteses "sociologia do Estado", por outro lado, registra uma reorientação inovadora, inédita até então nas universidades alemãs.

Escolhi esse curso para concluir, porque nele convergem todas as linhas, e o jogo da experiência política e da observação científica torna-se muito vivo. Mais de quinhentos alunos matricularam-se. Em Obra completa de Max Weber, na seção "Cursos", editaram-se agora os dois textos de anotações de ouvintes que chegaram até nós. É somente graças a essas anotações que conhecemos a disposição do curso como um todo e sabemos com que concentração linguística, utilizando-se de uma espécie de linguagem ditada, Weber proferiu as primeiras preleções até sua morte, em 14 de junho de 1920. Desde seus primeiros cursos, Weber sempre deu grande valor à organização da matéria ${ }^{16}$; por isso reproduzo aqui na íntegra a disposição de sua sociologia do Estado ${ }^{17}$ :

1. Conceito de Estado

2. Tipos de dominação legítima

3. Estamentos e classes

4. Estado dinástico e Estado de vassalagem

5. Patrimonialismo e funcionalismo público especializado

6. Burguesia e Cidade-estado

7. Divisão estamental de poderes e a ideia de representação

8. Divisão racional de poderes, parlamentarismo

9. Diferentes tipos de "democracia"

10. Poder político e autogestão

11. Poder político e poder hierocrático

12. [Poder político] e poder militar

Forma do Estado e forma econômica

13. Capitalismo politicamente orientado

14. Estado moderno e capitalismo racional

15. Estado de sovietes [Rätestaat]

16. Influência da estrutura interna pela política externa

Essa disposição volta a reunir uma vez mais, na "última cartada" de Weber, tudo que ele pretendeu dizer sobre a história cultural da modernidade, sob o ponto de vista da sociologia política. Isso exigiu muito dos ouvintes. Em primeiro lugar, e isso não se pode perceber a partir dos títulos, Weber aclara 
os conceitos básicos, sobretudo os tipos básicos de dominação: a dominação tradicional como força renitente e, por outro lado, a dominação racionalburocrática e a dominação carismática como, literalmente, as "duas grandes forças revolucionárias na história” (MWG III/7, pp. 94 ss.).

Recai sobre os alunos um sem-número de exemplos, não apenas os da conhecida história do desenvolvimento ocidental da Antiguidade a Lênin, como líder revolucionário do presente. A narrativa é interrompida por excursos etnográficos sobre culturas não europeias, por exemplo, as tribos iroquesas chefiadas por mulheres. Mas o tema central continua sendo a especificidade do desenvolvimento cultural europeu. Weber atribui essa peculiaridade, da qual decorrem a gênese e a estrutura do Estado moderno e do poder estatal moderno, à atuação concatenada de três fatores: as cidades ocidentais, com seus potenciais de democratização; as monarquias do início da Época Moderna, com seus potenciais de burocratização e o capitalismo moderno, assim como as ciências, com seus potenciais de racionalização.

Weber deriva daí uma teoria histórica da democracia, que ilustra com uma série de observações críticas sobre a constituição da República de Weimar, a primeira democracia na Alemanha. Sem rodeios, refuta o Estado de sovietes segundo o modelo da Revolução de Outubro de 1917. Sob as condições do capitalismo globalizado, Weber não vê nenhuma chance para uma revolução socialista seguida de uma dominação cesarista de camadas sociais sem propriedades, que é como define o sistema de sovietes. Para a questãochave - como é possível a dominação democrática no Estado moderno de massas? -, ele constrói outra alternativa. Já em "Política como profissão", ele considerou com agudeza duas formas básicas da ordem democrática, na seguinte fórmula: "Democracia do líder com a 'máquina', ou democracia sem líder" (Idem, p. 224). O curso evidencia ainda mais essa oposição. A fórmula oculta uma grande ambivalência entre política e economia, uma das tensões permanentes e insolúveis da modernidade, segundo o entendimento de Weber. Para ele, a Europa é uma formação dinâmica da racionalização de ordenações da vida - foi esta sua descoberta, ou seu insight. Ora, esses processos parciais não são compatíveis um com o outro: a racionalização da dominação política está em conflito com a racionalização dos interesses econômicos. Weber consegue descrever historicamente o conflito com seu conceito dileto de "luta" em torno de interesses e valores; mas isso também o leva a juízos conflitantes.

Politicamente, em sua obra tardia e, por fim, em seu curso sobre o Estado, Weber manifesta-se favorável à democracia plebiscitária do líder em um 
Estado racional constitucional. Concretamente, ele tem em vista a Inglaterra e, como tipo de uma política moderna e carismática, o premiê britânico William Ewart Gladstone, o "ditador do campo de batalha eleitoral”, a cujo "caráter ético" estava voltada "a fé robusta das massas" (MWG I/17, p. 209). Com isso, Weber demonstra que as democracias anglo-saxônicas - inclusive a norte-americana, com um presidente forte-, são para ele modelo de referência para um sistema político efetivo e para uma maximização da direção política na sociedade moderna de massas.

Economicamente, Weber se revela favorável ao capitalismo racional baseado em associaçóes livres de interesse. $\mathrm{O}$ título da segunda parte do curso "Forma do Estado e forma econômica" aponta para isso. Por sua vez, isso tende à "democracia sem líder", pois o capitalismo fundamentado no trabalho formalmente livre e em livres contratos de trabalho estimula a luta de interesses entre associaçôes e partidos, de uma maneira que reduz as oportunidades de autoridade da liderança política. De maneira concreta, Weber tem diante de si a transformação da Alemanha em uma democracia moderna sob o ônus da derrota na Primeira Guerra Mundial entre 1918 e 1919. Em seu curso, ele cria a categoria da "colegialidade de coalizão" (MWG III/7, p. 108) para expressar como a dominação não se costura pelas elites políticas, mas se reparte entre partidos heterogêneos, o que leva a uma minimização da direção política.

A obra tardia de Weber - para além da experiência imediata da nova ordem alemã de 1918 - desvela estruturalmente a tensão decisiva e permanente entre duas "racionalidades" opostas da modernidade, entre o Estado moderno e o capitalismo moderno: o Estado democrático "racional" exige uma elite política que domine, com qualidades carismáticas e uma administração eficiente, todas as associações intermediárias. O capitalismo "racional", de sua parte, institucionaliza justamente aquelas associações de interesse que a todo momento exigem novos compromissos e restringem os espaços de negociação política. Até hoje as democracias modernas estão determinadas em seu núcleo por esse antagonismo.

Ora, antagonismos desse tipo não são razão de indignação e espanto para Weber. Pelo contrário, estes lhe são bem-vindos como marca da modernidade. Ele não procura padrões ordenadores em uma homogeneização estatal ou em sínteses culturais, tal como a maioria dos intelectuais após a Primeira Guerra. Ordenaçôes modernas da vida colidem em seus interesses e orientações de valor. Exatamente aí Weber vê um princípio histórico de movimento que, na modernidade, protege as pessoas da paralisia poderosa 
nas "capas rígidas" da subserviência. Com essa visão da modernidade, Weber se situa reconhecidamente na tradição kantiana da "sociabilidade insociável" da vida humana - ainda que a ênfase recaia sobre a palavra "insociável". Cientistas sociais que pesquisam conflitos, como Ralf Dahrendorf, encontram aí um bom motivo para se apoiar sobre os ombros de Weber (cf. Hübinger, [prelo]).

Weber deve ter causado uma forte impressão nos ouvintes de seu curso "Sociologia do Estado" que eram "musicalmente" sensíveis a essas ambivalências da modernidade. O historiador Percy Ernst Schramm estava no segundo ano quando assistiu ao curso; ele anotou em seu diário: "Morreu depois de algumas semanas, mas sua personalidade exerceu sobre mim enorme influência; cientificamente, um estímulo imenso, nada era definido - muitos pontos de vista. Este foi um homem!"18.

Resumo

Max Weber e a história cultural da modernidade

Este artigo oferece um novo olhar sobre Weber como historiador. O fato de que a MWG reconstrói, de maneira bastante detalhada, o contexto histórico científico e intelectual torna mais evidente como os diferentes tópicos sobre os quais Weber trabalhou - a economia de mercado capitalista, as religiōes do mundo ou o Estado moderno - foram abordados em última instância "do ponto de vista da história cultural". Diante desse quadro, meu artigo explora quatro aspectos principais: história econômica; ou mais precisamente o sentido cultural da ação econômica como ponto-chave para o pensamento histórico de Weber como um todo (I); a insistência de Weber na primazia de problemas analíticos e da escolha de perspectivas como pressupostos intelectuais do conhecimento histórico (II); a questão fundamental da história cultural em geral: como as ideias se atualizam em conflitos e constelaçôes históricos e como a singularidade do desenvolvimento cultural europeu deve ser descrita em sua significação histórico-universal (III); a relevância da Primeira Guerra Mundial para os problemas e perspectivas de Weber: seu foco em uma teoria histórico-política do poder e da dominação e da gênese e estrutura do Estado moderno e da democracia (IV).

Palavras-chave: Max Weber; Max Weber Gesamtausgabe; História cultural; História intelectual; Sociologia do Estado.
18. Espólio de Percy Ernst Schramm, Arquivo Estatal de Hamburgo, L 36, f. 9. 


\section{Abstract}

Max Weber and the cultural history of modernity

This article takes a new look at Weber as a historian. The MWG's detailed reconstruction of the scientific and intellectual historical context provides a clear insight into how all the different topics on which Weber worked - the capitalist market economy, world religions, or the modern state - were ultimately treated "from the view-point of cultural history." In response the article examines four aspects: Economic history; or more precisely, the cultural meaning of economic action as a key to Weber's historical thinking as a whole (I); Weber's insistence on the primacy of analytical problems and of choices of perspectives as intellectual presuppositions of historical knowledge (II); the cardinal question of cultural history in general: how ideas take effect in historical constellations and conflicts, and how the peculiarity of European cultural development is to be described in its universal-historical significance (III); the relevance of the First World War for Weber's problems and perspectives: his concentration on a historical-political theory of power and domination and of the genesis and structure of the modern state and democracy (IV).

Keywords: Max Weber; Max Weber Gesamtausgabe; Cultural history; Intellectual history; Sociology of the State. 


\section{"Economia e sociedade"}

\section{A herança de Max Weber à luz da edição de sua}

Obra completa (MwG)

M. Rainer Lepsius

Tradução de Sibele Paulino

Sabemos que Economia e sociedade de Max Weber, organizado por Marianne Weber e posteriormente por Johannes Winckelmann, é um torso. Weber entregou para impressão apenas os três primeiros capítulos e o início do quarto; somente estes são "autorizados". Marianne Weber e Johannes Winckelmann consideraram que esses capítulos e os textos encontrados no espólio formavam uma obra coesa e os apresentaram como uma unidade. Mas não é esse o caso. É bastante improvável que o próprio Max Weber tivesse publicado uma obra como Economia e sociedade na forma que atualmente a conhecemos. O que temos diante de nós são versões inacabadas, originadas em diferentes fases de trabalho. A situação tornou-se ainda mais complicada quando, em 1956, Johannes Winckelmann, a partir do acervo dos textos legados por Weber, acrescentou à quarta edição de Economia e sociedade uma "Sociologia do Estado". Embora Weber a tenha planejado, não foi encontrado no espólio um manuscrito correspondente. Winckelmann compilou a seção 8 do capítulo "Sociologia da dominação" a partir de outras publicaçôes de Weber, em suas palavras, a "complementando dentro do possível" a partir de "propósitos conscientemente didáticos" (Winckelmann, 1972, p. xix). Temos, portanto, três acervos de textos em Economia e sociedade: 1) os textos que o próprio Weber, entre 1919-1920, entregou para impressão e corrigiu; 2) os textos que não se encontram ordenados no espólio e 3) a "Sociologia do Estado" compilada por Winckelmann. 
Disso, os organizadores da MWG extraíram três encaminhamentos. Em primeiro lugar, as compilaçôes de Winckelmann foram retiradas do texto e editadas no âmbito dos escritos originais de Weber, a saber: os textos "Política como profissão" e "Parlamento e governo na Alemanha reordenada", assim como a "História econômica". Em segundo lugar, separaram-se os capítulos entregues por Weber para impressão daqueles outros que integravam os acervos do espólio. Eles serão publicados em separado no volume 23 da seção I da MWG. Em terceiro lugar, os acervos do espólio dos anos 1909-1914 foram editados em cinco tomos no volume 22 da seção I. Com isso, já deve tornar-se visível que Economia e sociedade em sua versão tradicional não existe e, menos ainda, na versão de estudo difundida pela quinta edição de 1972.

Com efeito, a edição mantém como título principal o já instituído Economia e sociedade, mas diferencia, por meio do subtítulo, as versóes de antes da Primeira Guerra da versão do pós-guerra. Os tomos do volume 22 da seção I da MWG, com os textos oriundos do espólio, trazem o subtítulo "A economia e as ordens e poderes sociais", que Weber havia escolhido em 1914 para a sua contribuição no Grundriss der Sozialökonomik [Compendio de economia social]. No volume 23 da seção I da MWG, por outro lado, o subtítulo é "Sociologia". Como se pode depreender da correspondência com o editor, Weber falava com frequência da "minha sociologia". Ademais, há uma prova de impressão com esse título. "Economia e sociedade" era, em 1914, o título de uma seção específica do Grundriss der Sozialökonomik, que deveria compreender, ao lado da contribuição de Weber, também uma de Eugen von Philippovich. Após a morte de Weber, e por iniciativa de sua viúva, a contribuição de Philippovich foi publicada em outra parte do Grundriss, com isso, a seção "Economia e sociedade" passou a conter apenas a contribuição de Weber. E o que era o título da seção passou a ser o título da contribuição. Portanto, havia vários motivos para eliminar totalmente o título "Economia e sociedade" da edição e utilizar apenas o subtítulo atual. Entretanto, um título já enraizado há tantas décadas deveria ser mantido.

A MWG trabalhou minuciosamente a massa de material textual do espólio. Em formato gráfico maior, depois do redimensionamento das partes (eliminando a composição em tipos menores) e em razão do acréscimo dos comentários, temos agora cinco tomos imponentes: 1) "Comunidades"; 2) "Comunidades religiosas"; 3) "Direito"; 4) "Dominação"; 5) "A cidade". Weber não deixou instruções quanto à disposição dos textos que se encon- 